\title{
Human Sensitivity to Gearshift Loads
}

\author{
J. Giacomin and T.J.P. Mackenzie
}

Dept. of Mechanical Engineering

The University of Sheffield

Mappin Street

Sheffield, S1 3JD

Tel: 0114-222-7781

Fax: 0114-222-7890

E-mail: j.a.giacomin@sheffield.ac.uk 


\begin{abstract}
This paper describes an investigation of the ability of humans to distinguish different levels of gearlever load. A test rig with a forward-backward moving gearshift lever was constructed using the typical interior dimensions of European B segment automobiles. The rig used a system of weights and pulleys to provide a load which could be varied in steps of $1 \%$. Four reference loads were chosen which were considered representative of automotive gearshift operation: $0.5,1.0,2.0$ and $5.0 \mathrm{~kg}$. Twenty subjects took part in the study. Using a variation on the psychophysical method of limits, the subjects were asked to respond whether a test load was heavier or lighter than a reference load. The Weber Fraction was found to decrease monotonically from a value of 0.036 for the $0.5 \mathrm{~kg}$ reference load to a value of 0.029 at the $5.0 \mathrm{~kg}$ reference load. The average value across all reference loads was 0.032. Measurements of the gearshift force made by means of a knob containing a load cell suggested that the variation in he measured Weber Fraction might be attributable to the time behaviour of the force exchanged between the human subject and the control surface.
\end{abstract}

\title{
Relevance to Industry
}

The Weber Fraction for gearshift load discrimination is useful to the gearbox designer because it establishes a threshold for measurement accuracy, and sets a precision limit for quality rating criteria

Keywords: human perception, weber fraction, automobile, gearshift

\section{Introduction}

In the field of vehicular ergonomics, efforts are being made to define comfort indices and quality indices for vehicle primary controls. These metrics translate the measurable mechanical (objective) quantities of the command actuation into perceived (subjective) quantities which indicate the likely response of a test jury to questions about the command. Once defined, these metrics are used in the process of vehicle design. Examples of such indices are the clutch pedal comfort index defined by Giacomin and Bretin [7] and the gearshift criteria developed by Riccardo Consulting Engineers [12]. Implicit to such indices is human perception of force and movement.

The question of human sensitivity is one of psychophysics. Gustav Fechner proposed the earliest relationships between stimulus intensity and perceived intensity, and his work lead to the concept of just noticeable difference (JND). This is the amount that a stimulus must change for the change to be discriminable $50 \%$ of the 
time. Fechner [6] concluded that the JND, also known as the difference limen (DL), was linearly proportional to the stimulus intensity

$$
\frac{\Delta \mathrm{R}}{\mathrm{R}}=\text { constant }
$$

where $\mathrm{R}$ is the reference intensity, $\Delta R$ is the change in stimulus intensity (difference limen) and the dimensionless constant is the Weber Fraction (WF). Weber Fraction values for most stimuli are in the range from 0.01 to 0.25 [5].

Weber Fractions for force and weight have been reported by several researchers. Teghtsoonian [15] obtained a Weber Fraction of 0.02 in the case of weight, while Karowski et al. [11] found values from 0.02 to 0.04 for the manual lifting of boxes. For the lifting of small masses with the hands, Rees and Copeland [13] found a Weber Fraction value of 0.05 , while Ross and Brodie [13] found values from 0.08 to .115 for similar objects. In his book, Baird [1] reports a value of 0.07 for heaviness, while Jones and Hunter [10] have reported a Weber fraction of 0.15 for the human perception of forces applied to the hand-arm system. An interesting extension of the concept of Weber Fraction is furnished by the research of Hurmuzlu et al. [8], who obtained Weber Fraction values from 0.06 to 0.5 during the human control of a pneumatically driven robotic arm by means of a haptic interface.

Weber Fractions for pedal forces have been reported by at least two researchers. Jenkins [9] determined values (average WF value 0.06) for pushing isometric pedals while Southall [14] performed a study to determine the Weber Fraction for lorry clutch pedals (average WF value 0.07). Weber Fraction values were not found in the literature, however, for automotive gearshift actuation. Since the hand-arm system is lighter, more precise in its movements and generally characterised by a greater cutaneous sensitivity than the foot-leg system, it was hypothesised that the Weber Fraction might result smaller (higher sensitivity) in the case of gearshift actuation. It was also hypothesised that the WF values might result similar to those obtained in the literature for the lifting of small masses. The objective of this study was to determine an average Weber Fraction for automotive gearshift actuation loads in the for-aft direction.

\section{Method}

\subsection{Experimental Equipment}


A test rig was constructed using the typical dimensions of B segment European automobiles. Distances between the seat R-point and the gearshift lever were measured for several automobiles and average values were used. The seat was taken from a Fiat Punto. A simple backwards and forwards movement was chosen for the lever, which was designed to have a $10 \mathrm{~cm}$ throw.

Data taken from a Ricardo Consulting Engineers brochure [12] showed that the peak force experienced on an automotive gearlever during a shift could be over $100 \mathrm{~N}$. After consideration of both the minimum and maximum forces, and the need to keep the number of reference loads to a minimum, four reference loads were chosen: 0.5 , 1.0, 2.0 and $5.0 \mathrm{~kg}$. It was thought appropriate that the test load be varied in steps of $1 \%$ with respect to the reference since no Weber Fractions identified in the literature were smaller than $2 \%$. The reference and test loads were applied to the gearshift lever by means of a hangar, cable and system of pulleys. Figure 1 presents the geometry of the test rig.

\section{[insert Figure 1 here]}

Figure 2 presents the gearshift lever itself. The lower part of the lever was designed as a circular segment of radius equal to that of the shifter knob centre $(20 \mathrm{~cm})$. With the cable attached to this radius, the torque about the pivot was constant at all values of gearlever travel. The lever was machined from $17.5 \mathrm{~mm}$ thick aluminium plate, and the centre was cut out to reduce its mass moment of inertia. The lever ran on two ball races to reduce friction. The knob was a plastic item taken from a Ford Escort which was mounted on a $12 \mathrm{~mm}$ threaded shaft. The cable was a $6 \mathrm{~mm}$ nylon climbing rope which provided low friction and some elasticity, thus reducing the initial peak force required to overcome static friction. The stainless steel pulleys were all $60 \mathrm{~mm}$ in diameter and ran on $8 \mathrm{~mm}$ shafts. All supporting frames were constructed from $25 \mathrm{~mm}$ box section mild steel, arc welded and bolted to an aluminium floor base plate. A screen was erected between the seat and the front structure so that the test subject could not see the operations of the researcher or the weights being applied.

[insert Figure 2 here]

In addition to the standard plastic gearknob, a second instrumented knob was machined from a length of circular cross-section steel of $40 \mathrm{~mm}$ diameter. The outer surface of the knob was split and an Entran ELH-TCII-500 load cell was accommodated so as to measure the force acting between the outer shell of the knob and the lever. Signal amplification was performed by means of an Entran MSC6 amplifier and data acquisition was performed 
using a Techtronix TDS210 digital oscilloscope. One force time history was recorded for each reference load from each subject. From the oscilloscope, the data was transferred to an excel spreadsheet on a PC for analysis.

\subsection{Experimental Test Protocol}

A variation on the Method of Limits [1,2,4] was chosen for the study. Typical application of the method of limits consists of an ascending series where the test stimuli is always less than the reference stimuli, and a descending series where the test stimuli is always greater than the reference stimuli. In contrast to Southall's work on the clutch pedal in which the subject was given three choices of response, "lighter", "same", or "heavier", this study employed a forced choice method where the "same" response was not allowed. This decision was taken based on the work of Brown [3] who showed that the "same" response was unstable, and that subjects are tempted to give the same number of "same" responses as "heavier" and "lighter," thus reducing the apparent sensitivity. In this study, the test series continued until four successive responses of "heavier" or "lighter" were made. No feedback regarding the "correctness" of the subject's response was given.

The results were expressed as a probability function where $y$ is the probability of a "heavier" response given a test stimuli of intensity $x$. By convention, the comparison stimuli associated with $\mathrm{P}(x)=0.50$ is called the point of subjective equality (PSE) and the upper and lower limits of the interval of uncertainty (IU) are defined as the stimulus intensities at $\mathrm{P}(x)=0.75$ and $\mathrm{P}(x)=0.25$ respectively [1]. The just noticeable difference (JND), or difference limen (DL), is one half the interval of uncertainty. The Weber Fraction is then defined as

$$
\mathrm{WF}=\frac{\mathrm{DL}}{\text { Ref. }}
$$

where Ref. is the reference stimulus. Although the method of limits allows the reversal of the presentation order of reference and comparison stimuli, Southall concluded that neither the DL nor the PSE was dependent on the order of presentation for the clutch pedal. A decision was taken that the effect would probably also be small in the case of gearshift loads, therefore order reversal was not performed in this study.

The values for the reference loads were chosen to be representative of gearshift disengagement, neutral, synchronisation and double bump [12], they were: 0.5, 1.0, 2.0 and $5.0 \mathrm{~kg}$. The starting values for the comparison loads were determined from pilot trials to be $10 \%$ either side of the reference, since the reference and the test loads were always clearly distinguished at values less than $10 \%$. Each subject was tested at two different reference loads, chosen randomly. Both an ascending and a descending series were performed, and the 
order of presentation, whether ascending first or descending, was also randomised. Table 1 presents the tests performed by all 20 subjects.

\section{[insert Table 1 here]}

Each subject was issued an instruction sheet and a consent form which were read and signed. They were then asked to sit on the seat and adjust it so that they could comfortably move the lever between the end stop and the visual travel limit mark. A realistic speed and smoothness of movement was demonstrated, and they were advised to keep the left hand on the gearshift knob throughout the test. Subjects were then given sample reference and comparison loads so as to familiarise themselves with the test. After completing both series for the first test, there was a short break before moving on to the second test.

\subsection{Subjects}

Twenty subjects participated in the study, and took on average thirty minutes to complete the two tests. The subjects consisted of sixteen men and four women of diverse nationality. The mean age was 24.3 years, and the range was from 20 to 38 years. All wore light indoor clothing and none suffered from any known disability.

\section{Results}

Each reference load was tested a total of 20 times, 10 tests in ascending sequence and 10 in descending sequence (see Table 1). With respect to the reference load, the results from each comparison were recorded as either $z=1$ in the case of a "heavier" response or $z=0$ in the case of a "lighter" response. The responses to all test loads were determined, and the probability y of a heavier response at a comparison intensity $x$ was taken to be

$$
y=\left(\frac{\sum z}{20}\right)_{x}
$$

The results are shown in Figures 3 to 6 along with a best-fit line.

[insert Figure 3 here] [insert Figure 4 here] [insert Figure 5 here] [insert Figure 6 here]

Table 2 summarises the results. The mean Weber Fraction was 0.032 with a standard deviation of 0.002 . The PSE was consistently found to be lower than the reference intensity. As shown in Figure 7, the Weber Fraction was found to decrease with increasing stimulus intensity.

[insert Table 2 here] [insert Figure 7 here] 
Figures 8 and 9 present example force time histories measured at the instrumented lever knob during a $0.5 \mathrm{~kg}$ and a $5.0 \mathrm{~kg}$ test. Two observations could be made from all acquired data, the first was that an overshoot behaviour always produced dynamic peak forces in excess of the theoretical reference load while the second was that the force variation was greater in the case of the lighter reference loads.

[insert Figure 8 here] [insert Figure 9 here]

\section{Discussion}

The mean Weber Fraction found for gearshift loads in this study, taken by averaging the results from each of the four experimental reference conditions, was found to be 0.032. This can be compared to average WF values found in the literature for the lifting of weights. For the lifting of weights, Teghtsoonian obtained a value of 0.02 , Baird reported a value of 0.07, Rees and Copeland found a value near 0.05, and Ross and Brodie determined values from 0.08 to .115 from their experiments. For pedal operation, Jenkins found a Weber Fraction value of 0.06 for an isometric pedal while Southall obtained 0.07 from a test rig which recreated lorry clutch loads and travel. It can be seen that the mean value of 0.032 is within the range of literature values for similar stimuli, but that it lies near the low end of the scale. This suggests that human sensitivity to gearlever movement is high compared to that of other activities.

Variations in Weber Fraction value can often be attributed to differences in the experimental equipment and in the psychophysical testing method used. An example of WF variations for similar stimuli are the results obtained for pedal operation by Jenkins (0.06) and by Southall (0.07). In this case the differences are caused by both the nature of the physical stimuli (isometric pedal versus dynamic pedal) and the former's use of the average error method as opposed to the latter's use of the method of limits. Despite differences in method, the 0.032 value suggests a high level of sensitivity on the part of the hand-arm system. Besides precise cutaneous sensing at the hand surface, perception of the gearshift load was probably also enhanced by the ergonomically correct placement of the lever, which produced natural movements.

As shown in Figure 7, the Weber Fraction was found in this study to vary from 0.036 to 0.029 across the reference loads. A reduction of the Weber Fraction with increasing load (stimulus intensity) has been identified in numerous studies involving the perception of weight or mass. The variation from 0.036 to 0.029 is similar in percentage terms to those found by Rees and Copeland and by Ross and Brodie for the lifting of weights. In Southall's work for a clutch pedal, the variation was from 0.074 to 0.063 . It is a well-known fact that Weber 
Fractions increase as the stimulus intensity is lowered towards the perception threshold [1] due to the low energy values acting on the human receptors. The current results may be an example of this behaviour.

Figures 8 and 9 also suggest another possibility. The force at the interface between the hand and the lever did not remain constant during the throw, but instead varied due to the dynamic forces associated with the acceleration and deceleration of the principal system masses. A feature of the force time histories was the overshoot which occurred for all recorded tests. It was found that the overshoot, as a percentage, was larger at the lower test loads. Since the time between the onset of the movement and the point of maximum overshoot was always found to be less than $200 \mathrm{msec}$, it can be suggested that the initial movement was ballistic in nature and thus suffered, as a consequence, a high variability from test to test. The variability was larger at the lower test loads, perhaps due to a worse match between movement pre-programming and effective load. It can be hypothesised that the force overshoot, caused in part by the mismatch between expected lever load and test load, made it difficult to identify small differences between the reference and test stimuli, thus reducing the effective sensitivity of the hand-arm system.

\section{Conclusions and Recommendations}

From the results of this investigation it would seem reasonable to suggest an average Weber Fraction of 0.032 for the for-aft motion of an automotive gearlever at typical loads and at an average speed of travel. The WF variation across the range of test loads was found to be from 0.036 to 0.029 . It was also found that the WF tended towards smaller values (increased sensitivity) with increasing load acting on the gearlever.

As expected, the Weber Fraction for gearshift actuation was found in this study to be smaller (0.032) than the values for pedals such as the clutch that have been reported in the literature (0.06-0.07). This provides additional confirmation of the need to assign delicate control tasks to hand rather than foot controls. The Weber Fraction values obtained in this study can be used as part of the gearshift evaluation process to determine whether small synchronisation effects will actually be noticed or not.

Further areas of investigation include human sensitivity to lateral gearlever movements, and the effect of lever throw velocity on the Weber Fraction.

\section{Acknowledgements}

The authors would like to thank Mr David Nuttall for his assistance with the design and manufacture of the test rig. 


\section{References}

[1] Baird, J.C., 1997, Sensation and Judgement: Complimentary Theory of Psychophysics. Lawrence Erlbaum Associates, Mahwah, New Jersey

[2] Baird, J.C. and Noma, E., 1978, Fundamentals of Scaling and Psychophysics. John Wiley, New York

[3] Brown, W., 1910, The Judgement of Difference. Publications in Psychology, The University of California, 1, pp.1-71.

[4] Coren, S., Porac, C., and Ward, L. M., 1979, Sensation and Perception. Academic Press, New York

[5] Durlach, N.I. and Mavor, A.S. 1995, Virtual Reality: scientific and technological challenges, National Academy Press, Washington D.C.

[6] Fechner, G.T., 1860, Elemente der Psychophysik, Translated by H.E. Alder 1966, Elements of Psychophysics. Holt, New York

[7] Giacomin, J. and Bretin, S., 1997, Measurement of the Comfort of Automotive Clutch Pedal Actuation, Proceedings of the $4^{\text {th }}$ International Conference on Comfort in the Automotive Industry, Bologna, Italy.

[8] Hurmuzlu, Y., Ephanov, A. and Stoianovici, D. 1998, Effect of a pneumatically driven haptic interface on the perceptual capabilities of human operators, Presence, Vol. 7, No. 3, June, pp. 290-307

[9] Jenkins, W.O., 1947, The Discrimination and Reproduction of Motor Adjustments with Various Aircraft Controls, American Journal of Psychology, 60, pp. 397-406.

[10] Jones, L.A. and Hunter, I.W. 1993, A perceptual analysis of viscosity, Exp. Brain Res, Vol. 94, pp. 343351

[11] Karwowski, W., Shumate, C., Yates, J.W. and Pongpatana, N. 1992, Discriminability of load heaviness: implications or the psychophysical approach to manual lifting, Ergonomics, Vol. 35, Nos 7/8, pp. 729744

[12] Ricardo Consulting Engineers 1992, Shift Quality Development. Riccardo Consulting Engineers Ltd., Brighton.

[13] Ross, H.E. and Brodie, E.E. 1987, Weber fractions for weight and mass as a function of stimulus intensity, The Quarterly Journal of Exp. Psych., Vol. 39 (A), pp. 77-88

[14] Southall, D., 1985, The Discrimination of Clutch Pedal Resistances, Ergonomics, 28/9, pp. 1311-1317.

[15] Teghtsoonian, R., 1971, On the Exponents in Steven's Law and the Constants in Elkman's Law, Psychological Review, 78, pp. 71-80. 


\begin{tabular}{ccc}
\hline Subject Number & First Test* & Second Test* \\
\hline 1 & $0.5 \mathrm{~A}$ & $5 \mathrm{~A}$ \\
2 & $1 \mathrm{~A}$ & $2 \mathrm{~A}$ \\
3 & $2 \mathrm{~A}$ & $1 \mathrm{~A}$ \\
4 & $5 \mathrm{~A}$ & $0.5 \mathrm{~A}$ \\
5 & $0.5 \mathrm{D}$ & $5 \mathrm{D}$ \\
6 & $1 \mathrm{D}$ & $2 \mathrm{D}$ \\
7 & $2 \mathrm{D}$ & $1 \mathrm{D}$ \\
8 & $5 \mathrm{D}$ & $0.5 \mathrm{D}$ \\
9 & $0.5 \mathrm{~A}$ & $5 \mathrm{D}$ \\
10 & $1 \mathrm{~A}$ & $2 \mathrm{D}$ \\
11 & $2 \mathrm{~A}$ & $1 \mathrm{D}$ \\
12 & $5 \mathrm{~A}$ & $0.5 \mathrm{D}$ \\
13 & $0.5 \mathrm{D}$ & $5 \mathrm{~A}$ \\
14 & $1 \mathrm{D}$ & $2 \mathrm{~A}$ \\
15 & $2 \mathrm{D}$ & $1 \mathrm{~A}$ \\
16 & $5 \mathrm{D}$ & $0.5 \mathrm{~A}$ \\
17 & $1 \mathrm{~A}$ & $2 \mathrm{D}$ \\
18 & $0.5 \mathrm{~A}$ & $5 \mathrm{D}$ \\
19 & $2 \mathrm{~A}$ & $1 \mathrm{D}$ \\
20 & $5 \mathrm{~A}$ & $0.5 \mathrm{D}$ \\
\hline
\end{tabular}

* A, ascending trial before descending; $\mathrm{D}$ descending trial before ascending

Table 1) Testing Programme

\begin{tabular}{ccccc}
\hline Reference $[\mathrm{kg}]$ & PSE $[\mathrm{kg}]$ & IU [kg] & DL [kg] & Weber Fraction \\
\hline 0.5 & 0.496 & 0.036 & 0.018 & 0.036 \\
1.0 & 0.999 & 0.067 & 0.034 & 0.034 \\
2.0 & 1.990 & 0.124 & 0.062 & 0.031 \\
5.0 & 4.960 & 0.292 & 0.146 & 0.029 \\
\hline
\end{tabular}

Table 2) Summary of test Results 


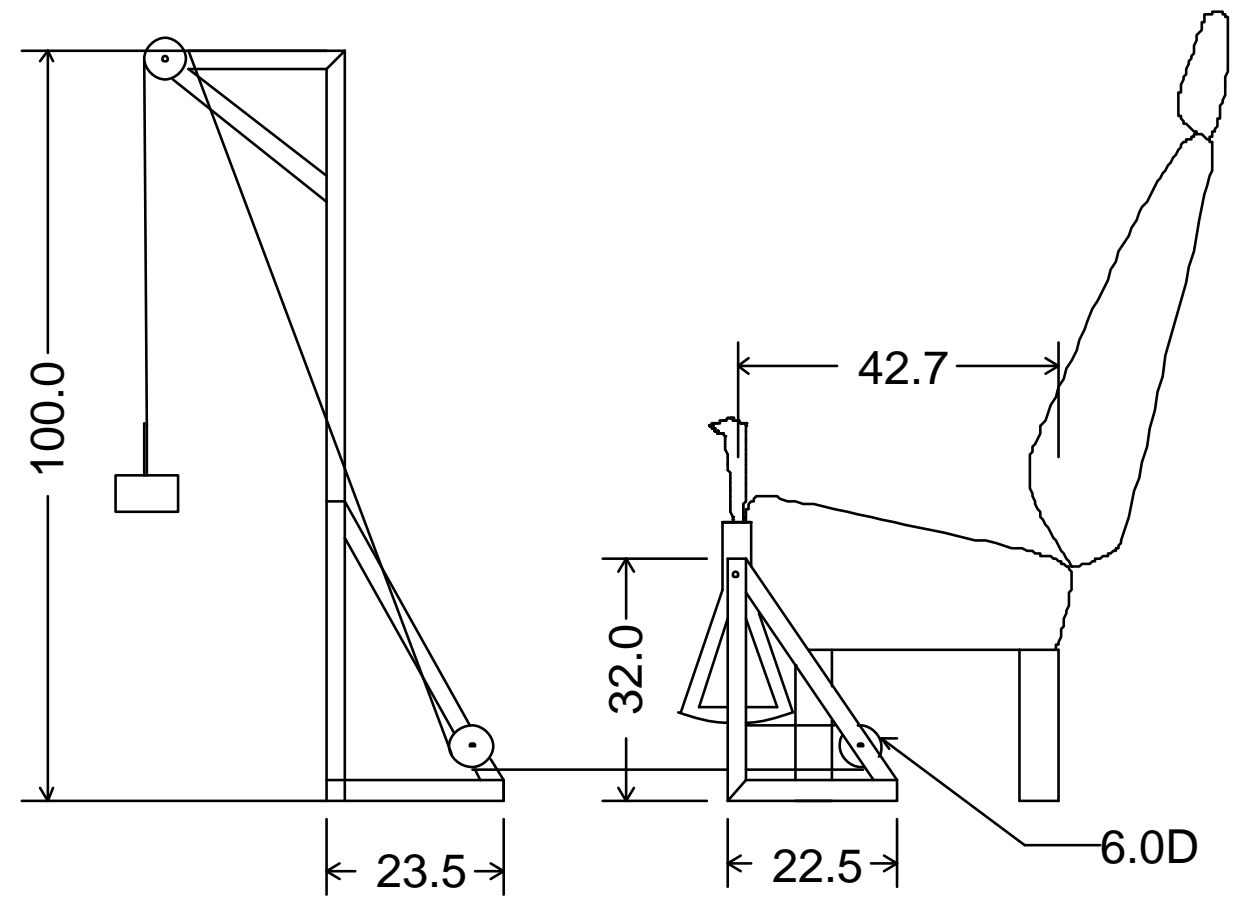

Figure 1) Test rig (dimensions in $\mathrm{cm}$.)

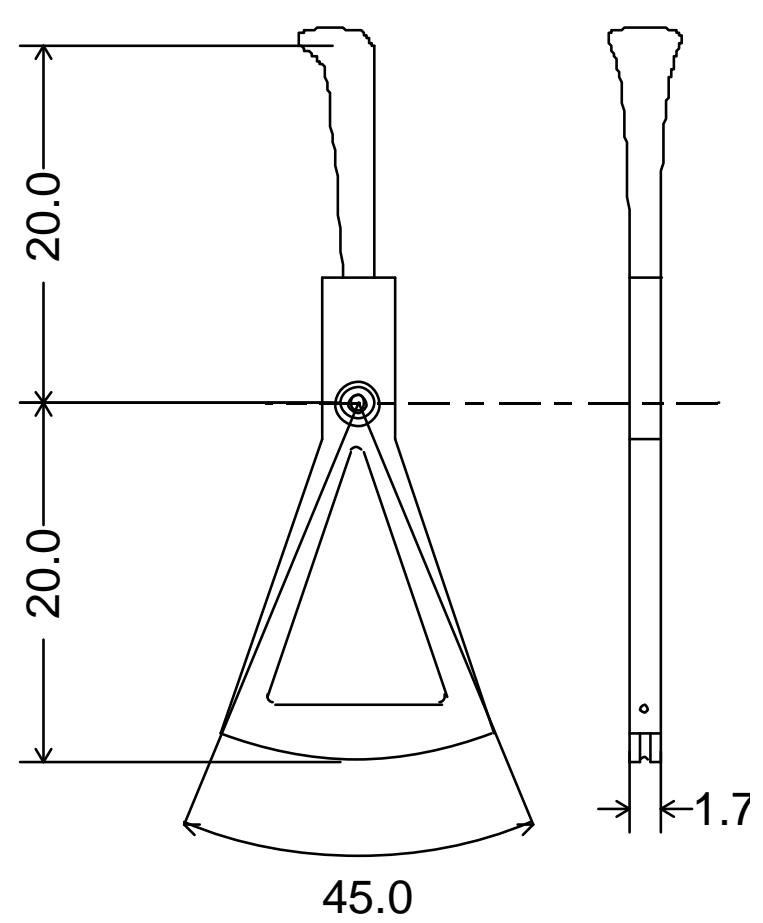

Figure 2) Dimensions of the gearlever in $\mathrm{cm}$ and degrees. 


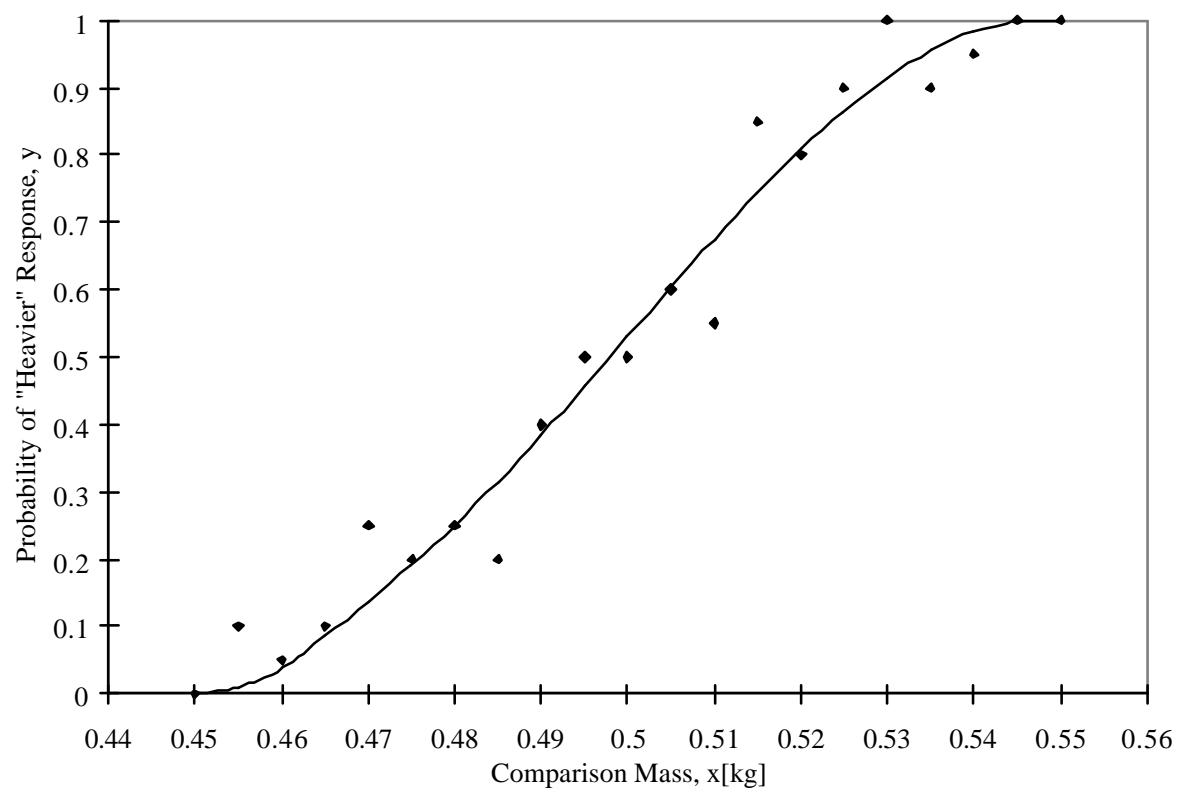

Figure 3) Probability function for the $0.5 \mathrm{~kg}$ reference load.

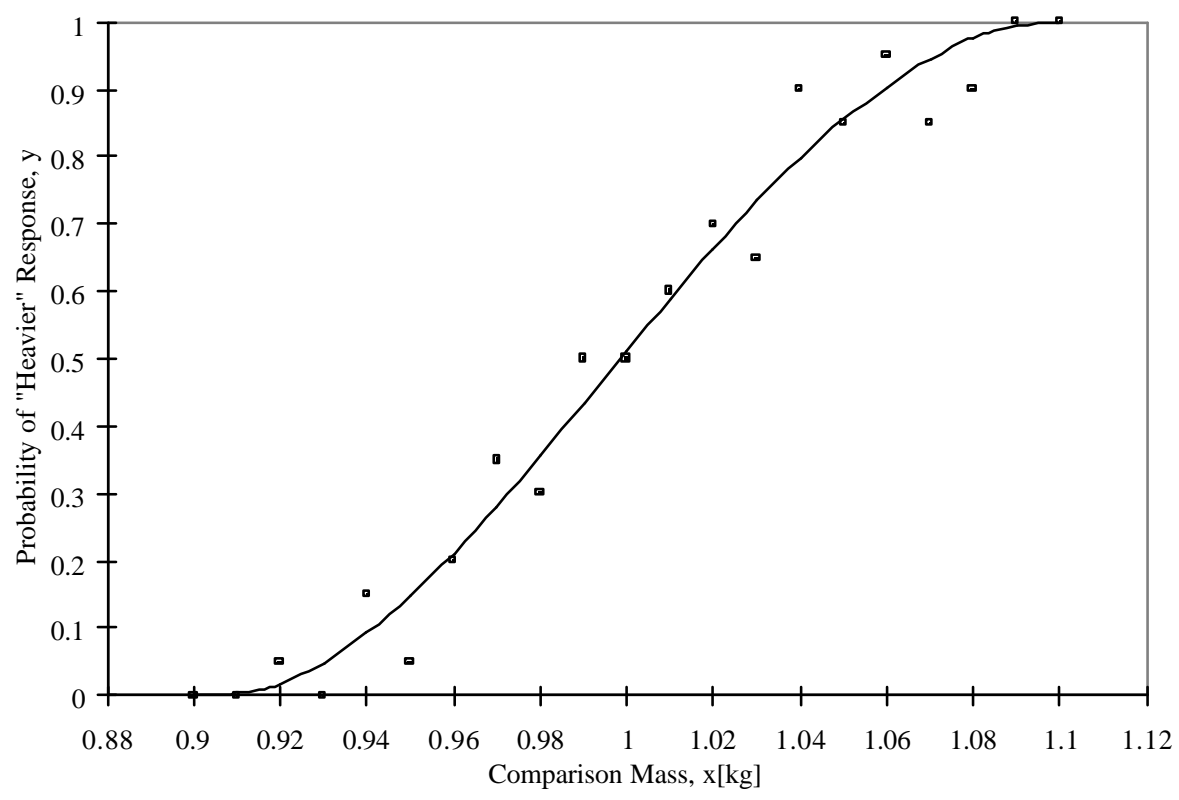

Figure 4) Probability function for the $1.0 \mathrm{~kg}$ reference load. 


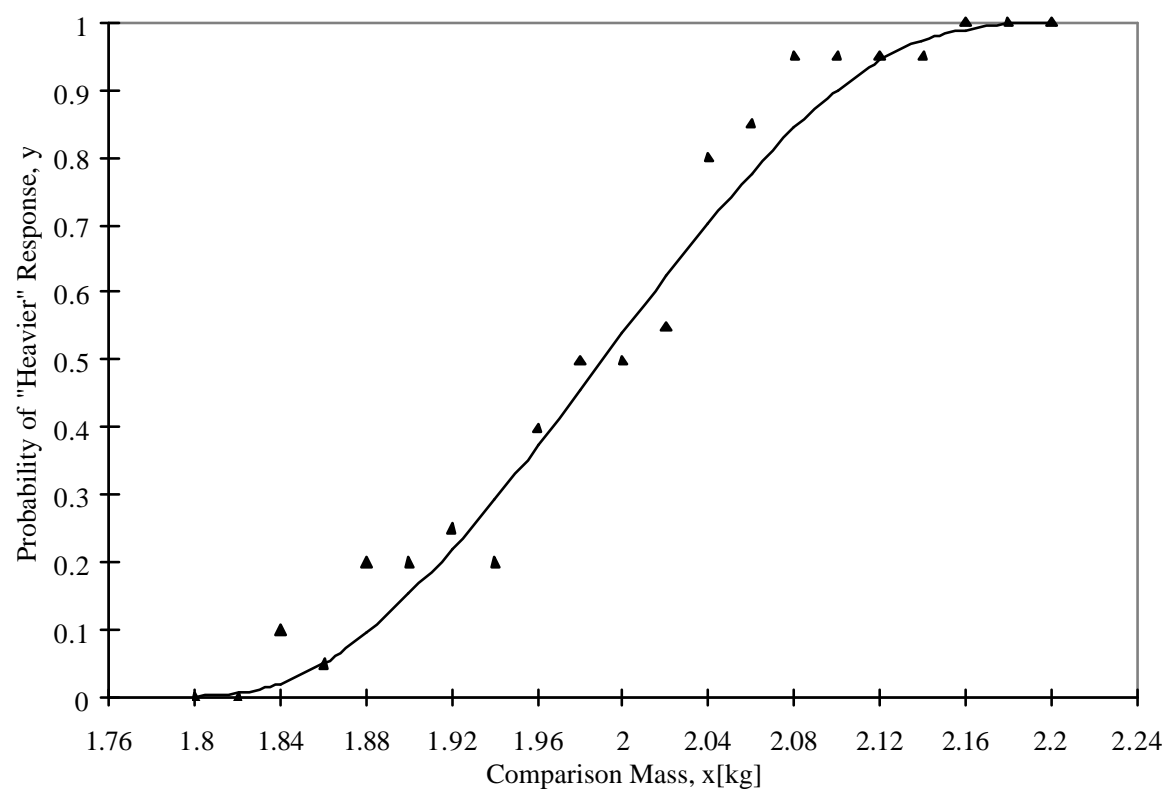

Figure 5) Probability function for the $2.0 \mathrm{~kg}$ reference load.

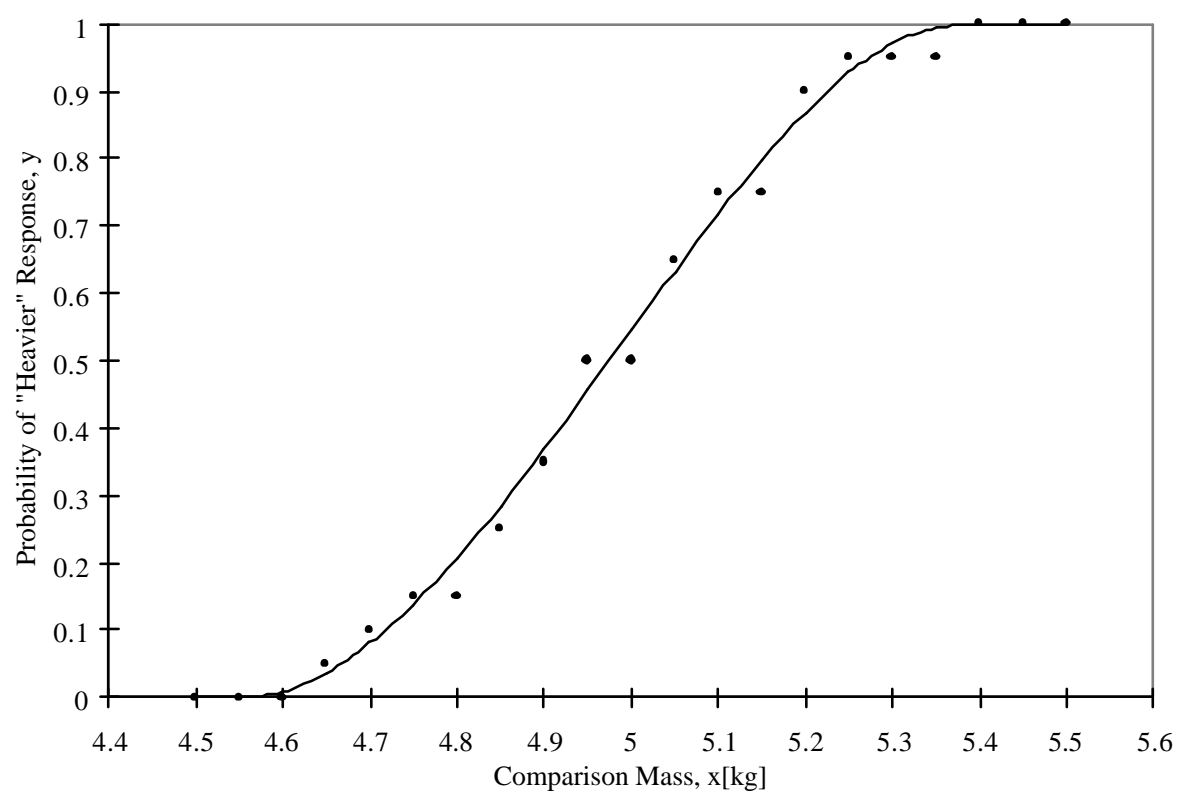

Figure 6) Probability function for the $5.0 \mathrm{~kg}$ reference load. 


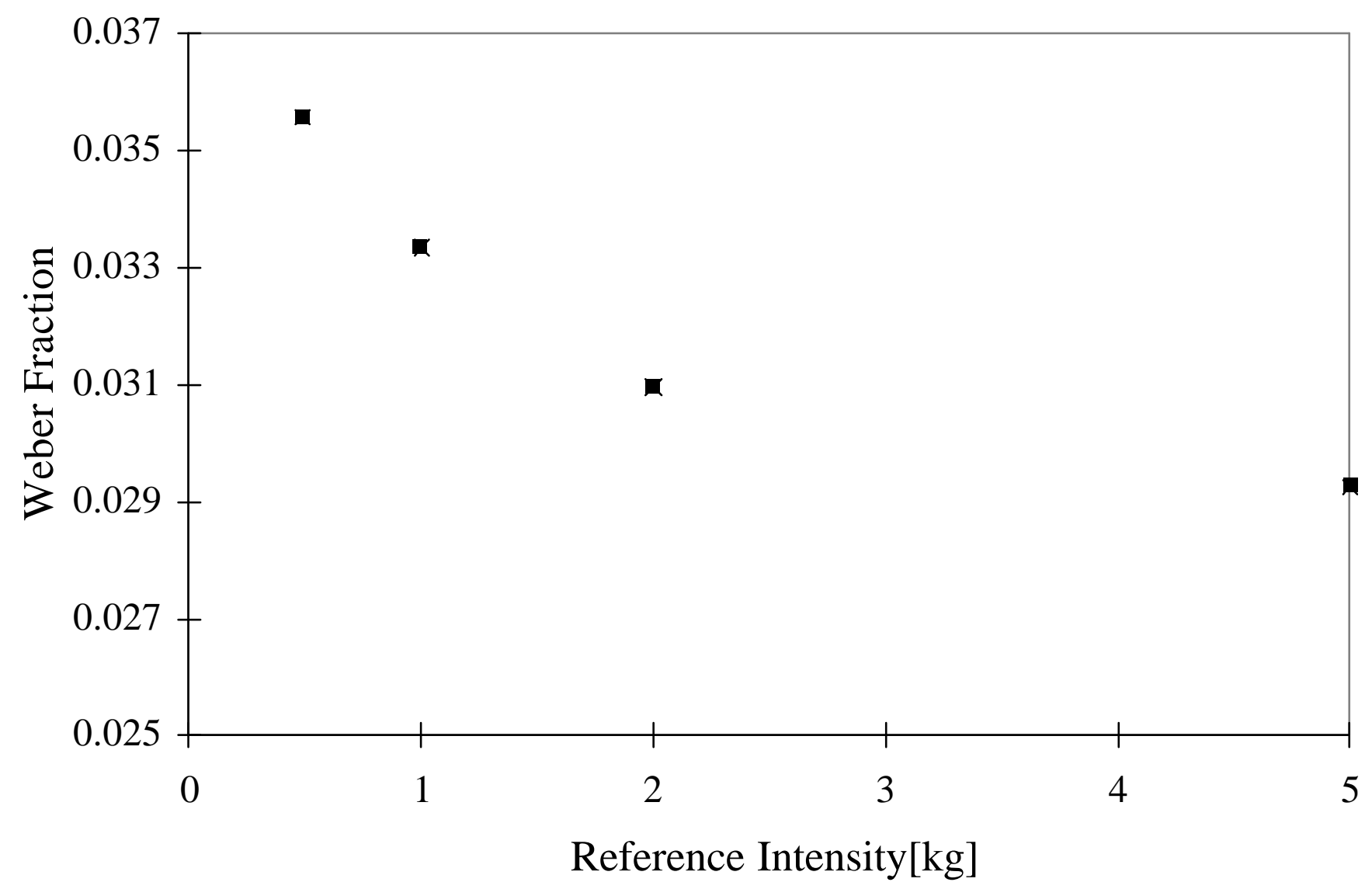

Figure 7) Weber Fraction plotted as a function of the reference load. 


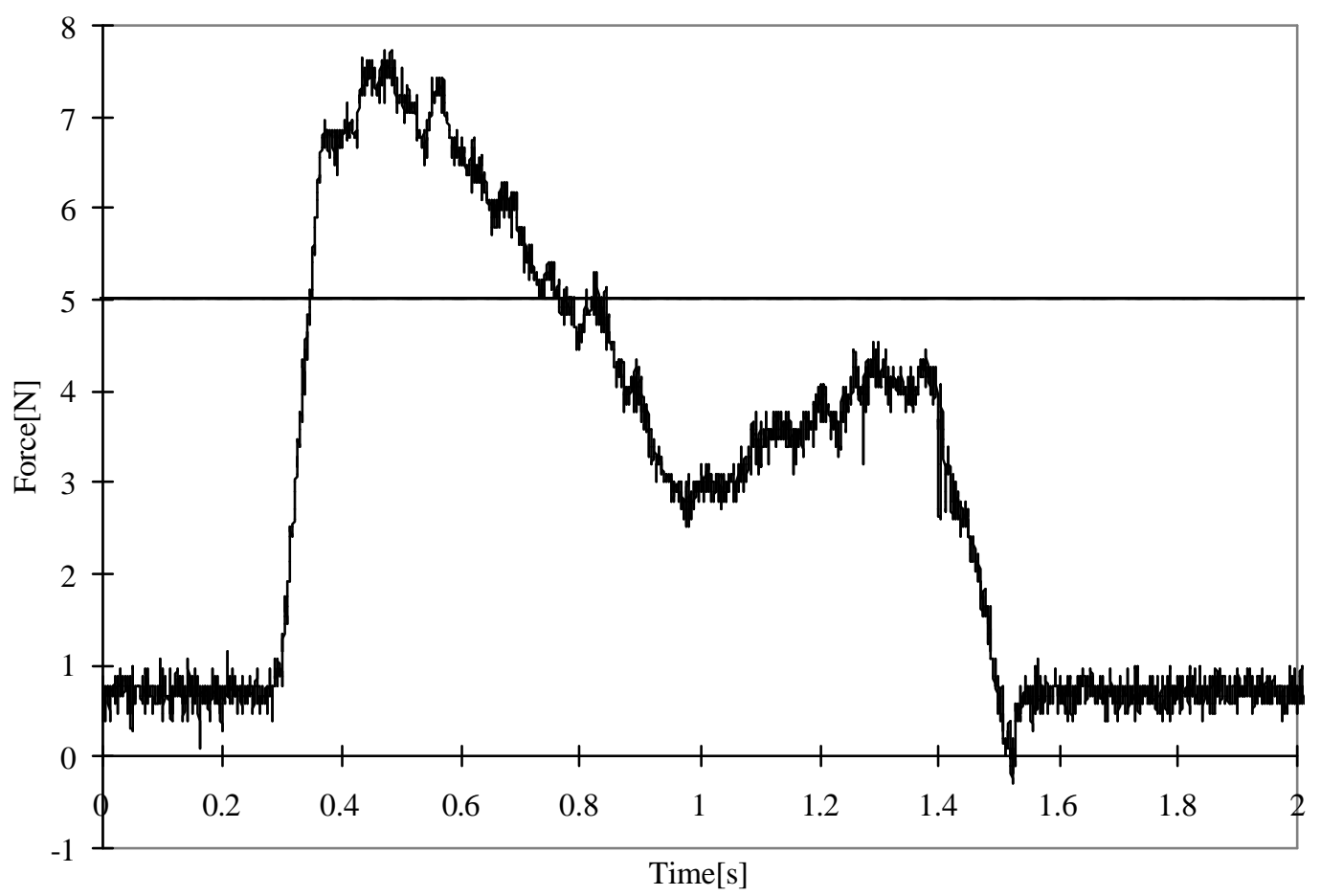

Figure 8 ) Force time history measured at the lever knob during a $0.5 \mathrm{~kg}$ test.

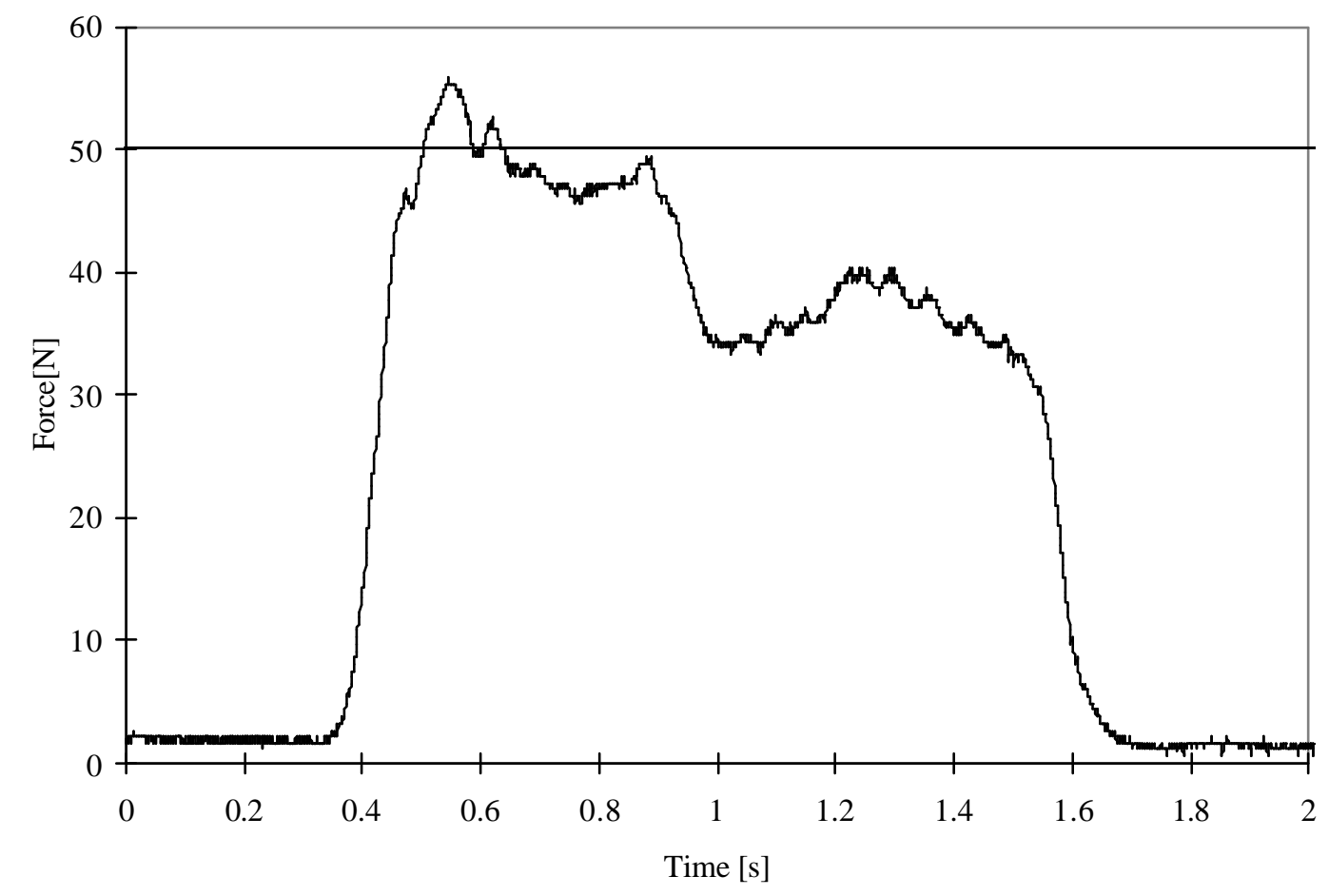

Figure 9) Force time history measured at the lever knob during a $5.0 \mathrm{~kg}$ test. 